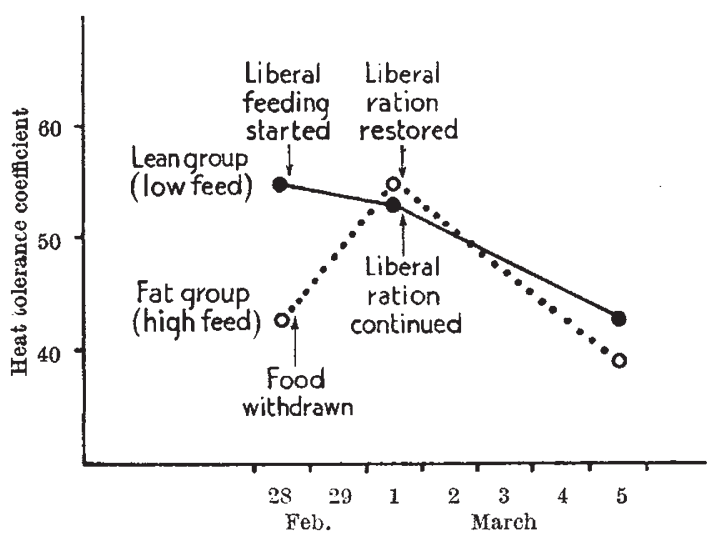

Fig. 1. Influence of the current rate of feeding on the heat tolerance of two groups of cattle reared on different planes of

March 1, when the heat-tolerance test was repeated. This time the heat tolerance of both groups was good and the difference between the mean of the fat group (55) and the mean of the thin group (53) was not statistically significant. The notable result was the 12-point improvement in heat tolerance of the fat animals.

After this test, both groups were placed on the liberal ration until a third heat-tolerance test was conducted four days later, on March 5. This time both groups showed poor heat tolerance. The mean heat-tolerance coefficients were 39 and 43 for the fat and thin groups, respectively, the difference not being statistically significant.

The results, presented graphically in Fig. 1, show that high condition is not in itself a disadvantage to cattle in withstanding heat. A high current rate of feeding, however, in either fat or poor cattle may, under hot conditions, add seriously to the heat load of the animals. This is similar to the conclusion reached for hens, sheep and pigs by Robinson and $\mathrm{Le}^{2}$, who also reported that the proportion of protein contained in the diet was without effect on the heat tolerance of these three species.

The present experiment also showed that, following change to the liberal ration, the heat tolerance of the under-nourished animals was still high two days after the change, but was low by the sixth day. The lag is probably a reflexion of the time required for the digestive tract of cattle to condition itself to assimilating and utilizing more and better feed, following a long period of restriction.

These results emphasize, inter alia, the importance of standard feeding routine when seasonal or other periodic heat tolerance tests are to be made.

The environmental studies of which this experiment forms a part are being conducted at the Physiology Department, University of Queensland, and, as an officer of the Division of Animal Health and Pro. duction, Commonwealth Scientific and Industrial Research Organization, I am grateful to Prof. W. V. Macfarlane for his co-operation and help.

$$
\text { N. T. M. YEATES }
$$

Commonwealth Scientific and

Industrial Research Organization,

$$
\text { and }
$$

Physiology Department,

University of Queensland, Brisbane. May 8.

${ }^{1}$ Rhoad, O. A., Trop. Agric., Trinidad, 21, 162 (1944).

- Robinson, K. W., and Lee, D. H. K., J. Anim. Sci., 6, 2, 182 (1947).

\section{Identification of Pseudomonas pyocyanea by the Oxidase Reaction}

Althovgh the identification of Pseudomonas pyocyanea is generally very simple, the diagnosis of 'atypical' strains may take several days, and, as Schaub and Foley" stress, "its identification may present a problem". Yow and 'Townsend ${ }^{2}$, in their study on the sensitivity of Ps. pyocyanea to various antibiotics, limit the scope of their examinations: "Because of the difficulty in positively identifying the non-pigment-producing strains of Pseudomonas, only those producing either pyocyanin, fluorescin, or both, were included in this study". However, apyocyanogenic strains are common. These strains are either primarily deficient in producing pigment or may have lost their ability to do so. Haynes ${ }^{3}$ therefore points out: "Strains not producing pyocyanin, from whatever source, cannot be dismissed from consideration as Ps. pyocyanea."

Already Gordon and McLeod 4 have observed that Ps. pyocyanea, besides other bacteria, gives a positive oxidase reaction although much less markedly than the Neisserias.

I have increased the sensitivity of the oxidase reaction by the following technique. A piece of Whatman's No. 1 filter paper, about $6 \mathrm{~cm}$. square, is laid in a Petri dish. Two to three drops of 1 per cent tetramethylparaphenylenediamine dihydrochloride solution is dropped on the centre of the paper. The suspect colony is removed with a platinum rod and is smeared thoroughly on to the reagentimpregnated filter paper in a line $3-6 \mathrm{~mm}$. long. If the reaction is positive, the transferred colony turns dark purple in 5-10 sec. The reagent should be prepared every two weeks and kept in a dark, glassstoppered dropping bottle in the refrigerator.

All 436 Ps. pyocyanea strains examined gave a positive oxidase reaction with the technique described, while the other common Gram-negative rods are oxidase negative. The oxidase reaction can be used as a simple, rapid screening test in the diagnosis of Ps. pyocyanea.

Detailed investigations on the confirmatory test for Ps. pyocyanea will be published elsewhere.

\section{Nrcholas Kovacs}

Public Health Laboratories, Perth,

Western Australia. May 1.

${ }^{1}$ Schaub, J. G., and Foley, M. K., "Diagnostic Bacteriology", 4th edit., 178 (1952).

${ }^{2}$ Yow, $-E$. M., and Townsend, E. S., "Antibiotics and Chemotherapy", 3, 709 (1953).

- Haynes, W. C., J. Gen. Microbiol., 5, 939 (1951).

${ }^{4}$ Gordon, J., and Meleod, J. W., J. Path. and Bact., 31, 185 (1928).

\section{Structure of the Ascidian Octacnemus Moseley}

Тमе tunicate family Octacnemidae contains two genera, Octacnemus Moseley and Polyoctacnemus Thle, and four species, all from great oceanic depths. The species have been described by Moseley ${ }^{1}$, Herdman ${ }^{2}$, Metcalf $^{3}$, Ritter ${ }^{4}$, and Madsen ${ }^{5}$; but their structure is peculiar and has never been satisfactorily related to that of other tunicates.

Octacnemus, the better-known genus, has in particular the following characters not found in 